\title{
EDitorial EDitoriol
}

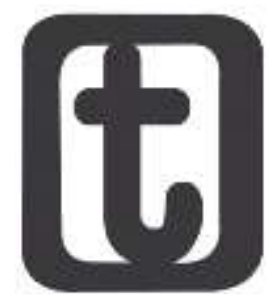

\section{SERVIÇO SOCIAL, MOVIMENTOS SOCIAIS E AS LUTAS SOCIAIS}

\author{
Sandra Lourenço de Andrade Fortuna* \\ Evilasio Salvador** \\ Maria Antônia Cardoso Nascimento*** \\ Diego Tabosa****
}

Diante da atual conjuntura liberal conservadora que pretende limitar a participação popular a Temporalis volume 19 número 38 entendeu como urgente e necessária essa publicação objetivando contribuir com o debate intelectual e político para o adensamento da produção de conhecimento na área de Serviço Social, que tem como eixo central discussões e produções teóricas acerca das temáticas relativas ao Serviço Social, movimentos sociais e as lutas sociais.

O tema escolhido para esta edição da Temporalis envolve um conjunto de preocupações que vêm orientando tanto a produção do conhecimento na área, como os processos de intervenção profissional do Serviço Social e de áreas afins. Toma centralidade nesta edição o debate sobre classe, consciência de classe, lutas sociais e suas configurações sóciohistóricas, bem como as organizações das/os trabalhadoras/es, dentre elas via partido político e sindicato. Os estudos sobre os chamados novos movimentos sociais também são fonte de preocupação nessa edição. Outro elemento central trata-se da política conselhista e seu desmonte na atual conjuntura brasileira que caminha na direção da destruição de direitos e a criminalização da organização das/os trabalhadoras/es.

\footnotetext{
* Professora Associada do Programa de Pós-Graduação em Serviço Social e Política Social do Departamento de Serviço Social da Universidade Estadual de Londrina (UEL).

** Professor do Departamento de Serviço Social e do Programa de Pós-Graduação em Política Social da Universidade de Brasília (UnB).

**** Professora titular da Faculdade e do Programa de Pós Graduação do Serviço Social da Universidade Federal do Pará (UFPA).

**** Professor do Curso de Serviço Social do Departamento de Política e Ciências Sociais da Universidade Estadual de Montes Claros (Unimontes).
}

DOI 10.22422/temporalis.2019v19n38p6-10

(cc) B Br $\mathrm{A}(\mathrm{s})$ Autora(s)/O(s) Autor(es). 2019 Acesso Aberto Esta obra está licenciada sob os termos da Licença Creative Commons Atribuição 4.0 Internacional (https://creativecommons.org/licenses/by/4.o/deed.pt_BR), que permite copiar e redistribuir o material em qualquer suporte ou formato, bem como adaptar, transformar e criar a partir deste material para qualquer fim, mesmo que comercial. O licenciante não pode revogar estes direitos desde que você respeite os termos da licença.

Temporalis, Brasília (DF), ano 19, n. 38, p. 6-10, jul./dez. 2019. | ISSN 2238-1856 
Nesse sentido, elaborar reflexões teórico-políticas sobre as trajetórias e as tendências acerca da relação do Serviço Social com os movimentos e organizações da classe trabalhadora, com os espaços institucionalizados de participação na formação e na ação profissional do Serviço Social, pensando a intervenção profissional nos processos de mobilização e organização popular são fundamentais.

Abrindo a Seção Temática, deparamo-nos com as importantes contribuições de Maria Lúcia Duriguetto e Juliano Zancanelo Rezende com o artigo intitulado: Movimentos sociais e Serviço Social: a 'virada' de 1979. Diante da atual conjuntura na qual o conservadorismo, ganha eco, inclusive com expressões no serviço social, e na qual os direitos de cidadania sofrem profundos ataques, o referido artigo propicia reflexões sobre a importância das lutas e movimentos sociais e, em particular, o movimento sindical, afirmando a necessária sintonia cotidiana da profissão com os processos de resistências e de organização das classes subalternas para o fortalecimento da direção sócio-política do projeto profissional. Nesse texto, há o resgate de elementos do processo histórico da relação das organizações sindicais do Serviço Social com o movimento operário e popular e seu impacto para a ruptura com o conservadorismo na profissão simbolizada na "virada" de 1979, que teve como marco simbólico decisivo, a intervenção no III Congresso Brasileiro de Assistentes Sociais (III CBAS, 1979).

No artigo Movimentos Sociais e Serviço Social: uma análise das publicações sobre o tema, as autoras Maria Clariça Ribeiro Guimarães e Morena Gomes Marques atendem uma das demandas apresentadas pela Associação Brasileira de Ensino e Pesquisa em Serviço Social (ABEPSS) ao conjunto dos Grupos Temáticos de Pesquisa (GTP's) da área: o mapeamento dos temas pesquisados pela categoria profissional expressos nos anais dos Encontros Nacionais de Pesquisadoras/es em Serviço Social (ENPESS) de 2014 e 2016. Aponta o quadro geral da produção teórica acerca do tema e as principais tendências dos estudos sobre o Serviço Social e movimentos sociais publicados. Apresenta a importância do debate mais amplo da organização política da categoria profissional, na relação do Projeto Ético Político e a articulação do conjunto CFESS-CRESS com os movimentos sociais, assim como a compreensão dos movimentos sociais como espaço sócio ocupacional e/ou elemento transversal aos demais processos de trabalho do assistente social, obtendo nesta conjuntura significativa relevância.

O movimento estudantil ganha destaque no artigo: 40 anos do movimento estudantil de serviço social: desafios e perspectivas na atualidade. Nele Isabelle Cristina Custodio de Lima aborda a trajetória histórico-política dos 40 anos do Movimento Estudantil de Serviço Social (MESS) e 30 anos da Executiva Nacional de Estudantes de Serviço Social (ENESSO), focando nos desafios contemporâneo da sua organização política, com recorte na Região II. Por meio de pesquisa documental e da própria militância a autora reafirma a necessária apreensão das contradições que surgem de todo processo determinado pela luta de classes, e utilizar-se da nossa inteligência e aptidão de mobilização para produzir, em conjunto com sujeitos coletivos e individuais, estratégias com potencial de enfrentar esse processo.

As autoras Ana Cristina Oliveira; Francine Helfreich Coutinho dos Santos e Regina Bienenstein nos levam à uma reflexão sobre a necessária articulação ensino, pesquisa e extensão e seu significado social, por meio da análise sobre a experiência da extensão

Temporalis, Brasília (DF), ano 19, n. 38, p. 6-10, jul./dez. 2019. | ISSN 2238-1856 


\section{हorrogat temporalis}

universitária interdisciplinar vinculada a movimentos sociais no artigo: Movimentos sociais urbanos, extensão universitária e serviço social: a experiência interdisciplinar de assessoria técnica. Ressaltam a perspectiva de extensão universitária em permanente diálogo com os movimentos sociais, situando-os como protagonistas dos processos desenvolvidos e, estabelecendo uma relação diferenciada com a sociedade no sentido de potencializar sua capacidade organizativa na luta por direitos sociais ora negados pelo poder público.

As lutas sociais indígenas como forma de resistência diante das violações de seus direitos e como sendo expressão da questão social tornam-se centrais na análise de Rosa Maria Castilhos Fernandes e Mariana Martins Maciel, publicizadas no artigo: As políticas indigenistas e as lutas sociais indígenas: manifestações da questão social. Nesse estudo, as autoras dão visibilidade às políticas indigenistas uma vez que os ataques a esses povos também têm relação à destituição de um conjunto de legislações no âmbito da proteção social brasileira, além disso, destacam a emergência desta discussão no âmbito do Serviço Social.

Ainda sobre as resistências e lutas dos povos indígenas Solange Maria Gayoso da Costa, apresenta o artigo: Violência, discriminação, racismo e conflitos envolvendo os povos indígenas do Baixo Tapajós, tomando por base os dados sobre os conflitos vivenciados pelos povos indígenas da região do baixo rio baixo Tapajós no estado do Pará e suas formas de lutas. Povos esses que sofrem cotidianamente ameaças, violências diversas, criminalização e racismo.

Encerrando a sessão temática, as tecnologias da informação e comunicação são abordadas por Célia Barbosa da Silva Pereira e Franciani Bernardes no artigo: Movimentos sociais e o debate sobre a comunicação na atualidade. A partir de uma pesquisa de campo as autoras buscaram conhecer como movimentos sociais feministas consolidados têm se apropriado das tecnologias da informação e comunicação (TICs) como ferramentas de mobilização e organização política. Frente à eclosão de protestos massivos e comunicações dos movimentos sociais, especialmente a partir de 2011, via internet enquanto um espaço para a organização política, perceberam que esse ambiente não se tornou central e nem substituiu os mecanismos tradicionais de mobilização e divulgação, como o contato pessoal, telefônico, o uso cartazes, faixas, distribuição de panfletos, entre outros.

Os temas livres iniciam com as contribuições de Mirele Hashimoto Siqueira e Alfredo Aparecido Batista cujo artigo intitulado: O intelectual orgânico e as classes subalternas: a elaboração da nova cultura para o novo bloco histórico indica caminhos para a investigação da categoria intelectual orgânico a partir da elaboração gramsciana. Nele os autores afirmam que o Estado em seu sentido integral, a produção do imaginário coletivo popular pelos intelectuais orgânicos e a unificação das classes subalternas se revelam como expressão de uma elaboração teórico-prática carcerária que, imbuída de um salto qualitativo pelo processo de maturação política, se instaura como um fundamento teóricometodológico marxista em que Gramsci é, notadamente, refundador comunista.

Em: A realidade brasileira na formação profissional de assistentes sociais, Lucas Bezerra; Evelyne Medeiros Pereira e Leonardo Nogueira, destacam a importância dos estudos sobre as dimensões formativa e investigativa com base numa direção político-pedagógica na área

Temporalis, Brasília (DF), ano 19, n. 38, p. 6-10, jul./dez. 2019. | ISSN 2238-1856 
do Serviço Social acerca da realidade nacional enquanto um elo para deslindar as exigências históricas profissionais e macrossociais do tempo presente.

Com o objetivo de problematizar, à luz da perspectiva crítica, a relação entre os fundamentos das metodologias ativas e a formação profissional em Serviço Social, tendo por base os dados do INEP/2016 e do Censo EaD Brasil/2016, Everton Melo da Silva aponta no artigo: Crítica às metodologias ativas na formação profissional em serviço social elementos centrais para a necessária reflexão sobre essa forma de ensinar na formação profissional em Serviço Social que propicia o imediatismo, o fortalecimento do pragmatismo profissional e provoca confusões teóricas sobre a relação entre teoria e prática.

Apropriando-se do caráter contraditório de avanço político e social da educação superior pública e dos desafios enfrentados diante da ofensiva do capital sob direitos sociais conquistados historicamente, Alison Cleiton Araújo em: Os suspiros de uma década: nota crítica sobre o Curso de Serviço Social da UFG, analisa a trajetória que demarca os dez anos de criação do primeiro curso de graduação público em Serviço Social do estado de Goiás, inserido na Universidade Federal de Goiás (UFG). Situa o decênio do curso a partir da importância da ampliação e da interiorização de universidades públicas em todas as regiões do país, do crescimento exponencial das vagas ofertadas nas instituições federais, de políticas de acesso e permanência que possibilitaram a entrada de segmentos historicamente negligenciados nos espaços universitários. Todavia, problematiza que esse avanço se dá em meio à projetos privatistas e interesses norteados pelo mercado que consagraram as políticas educacionais no período analisado, como produto das mudanças orquestradas por organizações internacionais e nacionais em nome dos ciclos reprodutivos do capital.

Poliana Machado Gomes da Silva traz à cena nessa edição, a discussão sobre as resistências e possibilidades ético-políticas do Serviço Social no antagonismo ao ultraconservadorismo hetero-patriarcal estruturante das relações sociais no Brasil, no artigo: Ante à radicalização hetero-patriarcal: resistências e possibilidades ético-políticas no serviço social. A autora é contundente ao afirmar que a direção ético-política da profissão é materializada, sobretudo, a partir de campanhas, seminários temáticos, movimentos estudantis, conferências, resoluções e, em especial, através da articulação com os movimentos feministas e da incorporação de seus anseios.

O artigo: Mulheres e seletividade penal: 'raça' e classe no encarceramento feminino, de Ana Clara Gomes Picolli e Silvana Marta Tumelero, reiteram a centralidade das atuais condições e conjuntura do aprisionamento de mulheres no Brasil tendo em vista as principais características da população prisional feminina, visando refletir sobre os determinantes sociais e históricos que marcam estas mulheres, tendo por fundamento as estruturas que compõe a sociabilidade capitalista, como o racismo, sexismo e outras opressões que marginalizam corpos não hegemônicos.

Essa edição conta, especialmente com uma contribuição que muito nos honra: a entrevista com a Dra. Maria Beatriz Costa Abramides, assistente social aposentada, professora do Programa de Estudos Pós-Graduados em Serviço Social da PUCSP, Coordenadora do Núcleo de Estudos e Pesquisas em Aprofundamento Marxista, membro do GTP ampliado

Temporalis, Brasília (DF), ano 19, n. 38, p. 6-10, jul./dez. 2019. | ISSN 2238-1856 


\section{eөroosat temporolis}

de Movimentos Sociais e Serviço Social da ABEPSS, diretora da APROPUC-SP, autora de artigos e livros, o mais recente O Projeto Ético-Político do Serviço Social Brasileiro- Ruptura com o Conservadorismo, Cortez Editora, 2019. À Dra. Maria Beatriz os nossos mais profundos agradecimentos pelo compromisso histórico com as classes trabalhadoras, movimentos de luta e com a categoria profissional de assistentes sociais!

Somos gratas(os) às(aos) autoras(es) que contribuem historicamente com a Temporalis, revista mantida pela Associação Brasileira de Ensino e Pesquisa em Serviço Social, mas que pertence a toda categoria profissional de assistentes sociais e que resiste bravamente! Gratidão especial ao conjunto de avaliadoras(es) que, mesmo na super-sobrecarga de trabalho se comprometem com a qualidade de seus pareceres, mantendo o fluxo editorial e a possibilidade das publicações. Registramos também o importante apoio da equipe de suporte técnico e de editoração final da Ufes.

Agradecemos também a todos(as) que contribuem com a defesa intransigente da direção ético-política da nossa profissão, dos espaços coletivos de luta e da permanente e incansável defesa dos movimentos sociais.

Sigamos juntas(os) em movimento, na luta e na resistência!

Gestão 2019-2020 